\title{
A REVIEW OF TARGETED OBSERVATIONS
}

\author{
by Sharanya J. Majumdar
}

Targeted observations to improve numerical forecasts of high-impact weather events over the past two decades, particularly during the THORPEX era (2005-14), are evaluated.

$\mathrm{T}$ he concept of targeted observations lies in the question of "Where and when should one deploy and assimilate observations, in order to improve a numerical forecast of a weather event that is important to society?" The premise is that forecast errors of a particular event can grow, sometimes rapidly, when initial conditions are not properly constrained by observational data. To curtail rapidly growing forecast errors, regions in which analysis errors amplify into these large forecast errors must be identified. Observations can then be targeted and assimilated to reduce analysis errors in these important regions. In addition, observations in regions of initially large analysis errors that may evolve (perhaps slowly) into large forecast errors can also be targeted.

AFFILIATION: MAJUMDAR-Rosenstiel School of Marine and Atmospheric Science, University of Miami, Miami, Florida CORRESPONDING AUTHOR: Sharanya J. Majumdar, Dept. of Atmospheric Sciences, Rosenstiel School of Marine and Atmospheric Science, University of Miami, 4600 Rickenbacker Cswy., Miami, FL 33I49

E-mail: smajumdar@rsmas.miami.edu

The abstract for this article can be found in this issue, following the table of contents.

DOI:10.1175/BAMS-D-14-00259.I

A supplement to this article is available online (10.1 I75/BAMS-D-14-00259.2)

In final form 15 April 2016

(C2016 American Meteorological Society
Targeted observations make up a subset of the broader field of "adaptive sampling," which is widely used in areas including electrical and computer engineering applications, and in detecting behavior in localized animal clusters. Within the context of weather, adaptive observations refer to any supplementary observations that can be deployed at will, based on a certain phenomenon to be studied or predicted. The first aircraft reconnaissance missions into hurricanes and typhoons in the 1940s can be considered to be adaptive observations. One of the earliest examples of adaptive observations with an emphasis on weather forecasting was the launching of extra radiosondes in the United States and neighboring regions ahead of a tropical cyclone (TC) in the 1950s (B. Sheets 2015, personal communication). While these radiosondes were deployed adaptively, there was no technique to target the observations in particular areas. Later, during the National Oceanic and Atmospheric Administration's (NOAA) Synoptic Flow Experiment between 1982 and 1996, aircraftbased dropwindsonde observations were targeted around the TC in regions based on synoptic reasoning (Burpee et al. 1996).

The first large-scale attempt to investigate the utility of targeted observations in the extratropics was the multinational Fronts and Atlantic Storm Track Experiment (FASTEX) field campaign in 1997 (Snyder 1996; Joly et al. 1999), where one goal was to test the hypothesis that observations in selected "target 
regions" over the northern Atlantic would improve 1-2-day forecasts of frontal cyclones over Europe. FASTEX was the first field campaign to introduce new mathematical techniques designed to identify these target regions, within which the assimilation of observations was expected to yield the largest improvements to a selected forecast. Other important legacies of FASTEX included the international coordination of a variety of platforms to sample a chosen weather event through its life cycle, and the preparation of a database including observational data and gridded analysis fields that made use of the special data. The success of FASTEX, with forecast improvements of $10 \%-15 \%$ realized in several modeling systems as a result of the assimilation of the targeted observations, led to optimism that case-by-case targeting would yield substantial forecast gains. This gave impetus to a grand vision that the Global Observing System would ultimately be supplemented by networks on an adaptive basis, or even optimized into a fully adaptive network. An example would be the commissioning of more upper-air data in specific meteorological situations. It had been anticipated that these supplemental observations would be sufficiently important to society to justify the potential increases in cost and complexity. The initiation of the THORPEX ${ }^{1}$ era (Parsons et al. 2017) provided an organizational framework to aim toward this grand goal, via a series of international field campaigns and assimilation studies that focused on improving 1-4-day forecasts of phenomena such as winter storms, TCs, and precipitating systems. Each field campaign is summarized briefly below (see Table 2 ), including the types of targeted observations, the main forecast goals, and the evaluation results. Targeted observations have been reviewed periodically over the past decade; first by Langland (2005), followed by Rabier et al. (2008) with the THORPEX Data Assimilation and Observing Systems (DAOS) working group, and finally in a detailed technical report prepared by DAOS and several experts (Majumdar et al. 2011²).

The end of the THORPEX era (2005-14) provides an opportunity to review the successes and

\footnotetext{
${ }^{1}$ THORPEX, which was in operation between 2005 and 2014 under the auspices of the WMO, was "A World Weather Research Programme accelerating improvements in the accuracy of one day to two week high-impact weather forecasts for the benefit of society, the economy and the environment" (Shapiro and Thorpe 2004).

${ }^{2}$ The WMO/THORPEX report on targeted observations (Majumdar et al. 2011) is available at www.wmo.int/pages /prog/arep/wwrp/new/documents/THORPEX_No_I5.pdf.
}

shortcomings of targeted observations, and to assess whether the original grand vision has been realized. This article aims to offer a broad perspective that is more accessible to a wider readership than Majumdar et al. (2011). In the next section ("Techniques for targeted observing guidance"), the techniques used to select target regions are reviewed, followed by a summary of the prominent field campaigns ("Field campaigns" section). A synopsis of evaluations of the influence of assimilating targeted observations is then provided in the "Results from evaluations" section. Finally, conclusions and recommendations for the future are provided. Although the results summarized in this paper are synthesized from many studies, references are restricted to a subset of selected papers to preserve the readability. A full bibliography of around 200 papers is provided in the online supplement to this paper (http://journals .ametsoc.org/doi/abs/I0.II75/BAMS-D-I4-00259.2). An explanation of how the targeted observations are selected is presented in the first sidebar.

\section{TECHNIQUES FOR TARGETED OBSERV-} ING GUIDANCE. To predict the optimal locations and times for targeting prior to deployment, several mathematical techniques have been developed and widely published since the mid-1990s. Given the process of an operational assimilation-forecast cycle, a strategy for targeted observations would ideally account for i) the forecast uncertainty of a high-impact event at time $t_{v}$, ii) all observations to be assimilated up to and including the targeted analysis time $t_{a}$, iii) the characteristics of the data assimilation scheme, iv) the type and accuracy of the targeted observations, and v) the projected influence of assimilating the targeted observations at time $t_{a}$ on a future forecast of a specified metric at time $t_{v}$. Because of the prohibitively high computational effort that is required to account for all of these facets, it has been necessary to make crude assumptions such as the linear evolution of errors.

The main techniques employed prior to and during the THORPEX era are summarized in Table 1. Additionally, a large body of the literature on the techniques is listed in the accompanying bibliography (papers labeled with an M). The earliest techniques developed for use in FASTEX were based on dry dynamics and analysis sensitivity, in other words, how a modification to the analysis at time $t_{a}$ is estimated to affect forecast errors at time $t_{v}$. Over the subsequent few years, the observations and data assimilation scheme began to be incorporated into existing or new methodologies. Recent advances include the addition 


\section{HOW ARE TARGETED OBSERVATIONS SELECTED?}

$T^{\text {ho }}$ he procedure to select targeted observations is complex and imperfect. A basic example of a common forecast case scenario is illustrated in Fig. SBI. The case is selected by a forecaster or lead investigator, who at time $t_{i}$ identifies a potential highimpact weather event of importance to society at a future verification time $t_{v}$ (top-left map). A verification region is selected (red box). The objective is to target observations at a future analysis time $t_{a}$ to improve a forecast between $t_{a}$ and $t_{v}$ within this verification region. Using targeting guidance products based on models initialized at time $t$ (shading in bottom map), a decision on whether and where to deploy is then issued at the decision time $t_{\mathrm{d}}$. Because of the lead time involved with mission planning, this decision normally needs to be made more than a day prior to $t_{a}$. Observations such as those from dropwindsondes are then targeted in the sensitive area at time $t_{a}$.
After the conclusion of the experiment, the influence of assimilating the targeted observations at time $t_{0}$ is evaluated within the verification region at time $t_{v}$. In observing system experiments (OSEs), this is accomplished by comparing a forecast with routine and targeted data (green contours; top-right map) versus a forecast that is the same except that the targeted data are withheld (black contours; top-right map). Finally, it should be noted that many elements can be varied beyond the example illustrated in Fig. SBI, such as the weather system that is targeted, the types of guidance products used, the forecast window $\left(t_{v}-t_{a}\right)$, the types of observations to be targeted, and the evaluation procedure.
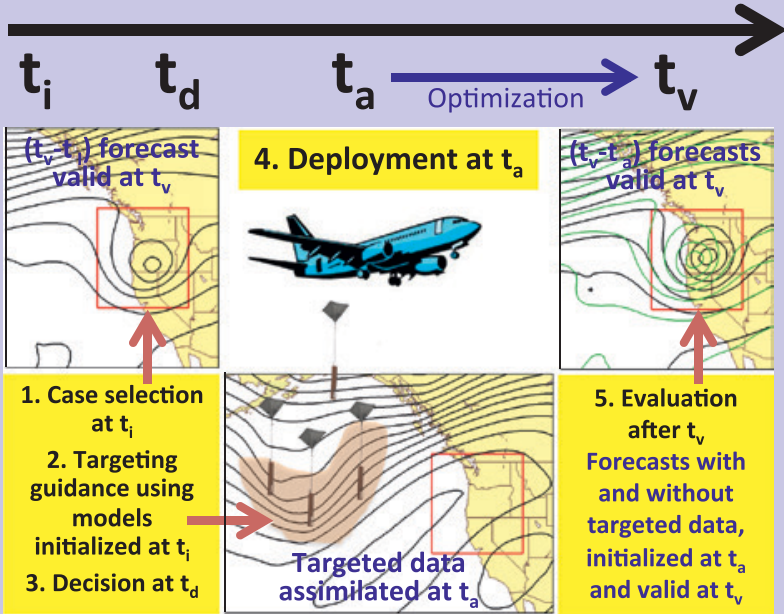

FIG.SB I.Schematic of the targeted observing procedure. of moisture, with applications to mesoscale weather. All of the techniques to date employ either adjoint methods or ensemble forecasts. Some are based on the direct sensitivity of a response function or forecast metric (e.g., total energy within the verification region) to observations or changes to the analysis, whereas others make quantitative predictions of the effect of assimilating targeted observations. Hybrids of certain techniques have been proposed, such as the inclusion of ensemble-based error covariance information within a singular vector (SV) framework. While these techniques possess theoretical similarities and differences, the consensus view is that they all possess limitations, especially when nonlinearity is significant.

The meteorological characteristics of the guidance products used during the field campaigns have been investigated and compared. In the extratropics, the widely used adjoint, SV, and ensemble transform Kalman filter (ETKF) products commonly identified baroclinic zones and jet features as targets, though smaller-scale aspects differed. As the forecast window $\left(t_{v}-t_{a}\right)$ increased, the targets could be traced farther upstream in the storm track, with multiple targets often appearing. For TCs, the guidance products often disagreed. For example, SV guidance identified the sensitivity in an annulus around the TC and upstream locations in the midlatitude trough for recurving TCs, whereas the ETKF identified features such as adjacent ridges and troughs, and regions downstream in the midlatitude storm track (Wu et al. 2009). The results were also dependent on the model used. The target regions were often of synoptic scale, which is usually beyond the range of coverage of a single aircraft mission. The consensus among the community is that the target regions generally tended to be in meteorologically sensible regions, though spurious targets could sometimes exist. Additionally, a limited number of studies have demonstrated that the assimilation of observations targeted within target regions has had a larger positive impact on forecasts than equivalent observations outside the target regions or selected at random.

After two decades of development and use, it is prudent to ask what lessons have been learned from the targeting techniques. First, the techniques have all proven to be practicable for real-time implementation during field campaigns. In many cases, this had been accomplished by using an adjoint model of lower resolution, or an ensemble of model output with limited fields. To expedite the mission planning, several field campaigns used automated software to draw or select flight tracks that traversed the maxima of the 


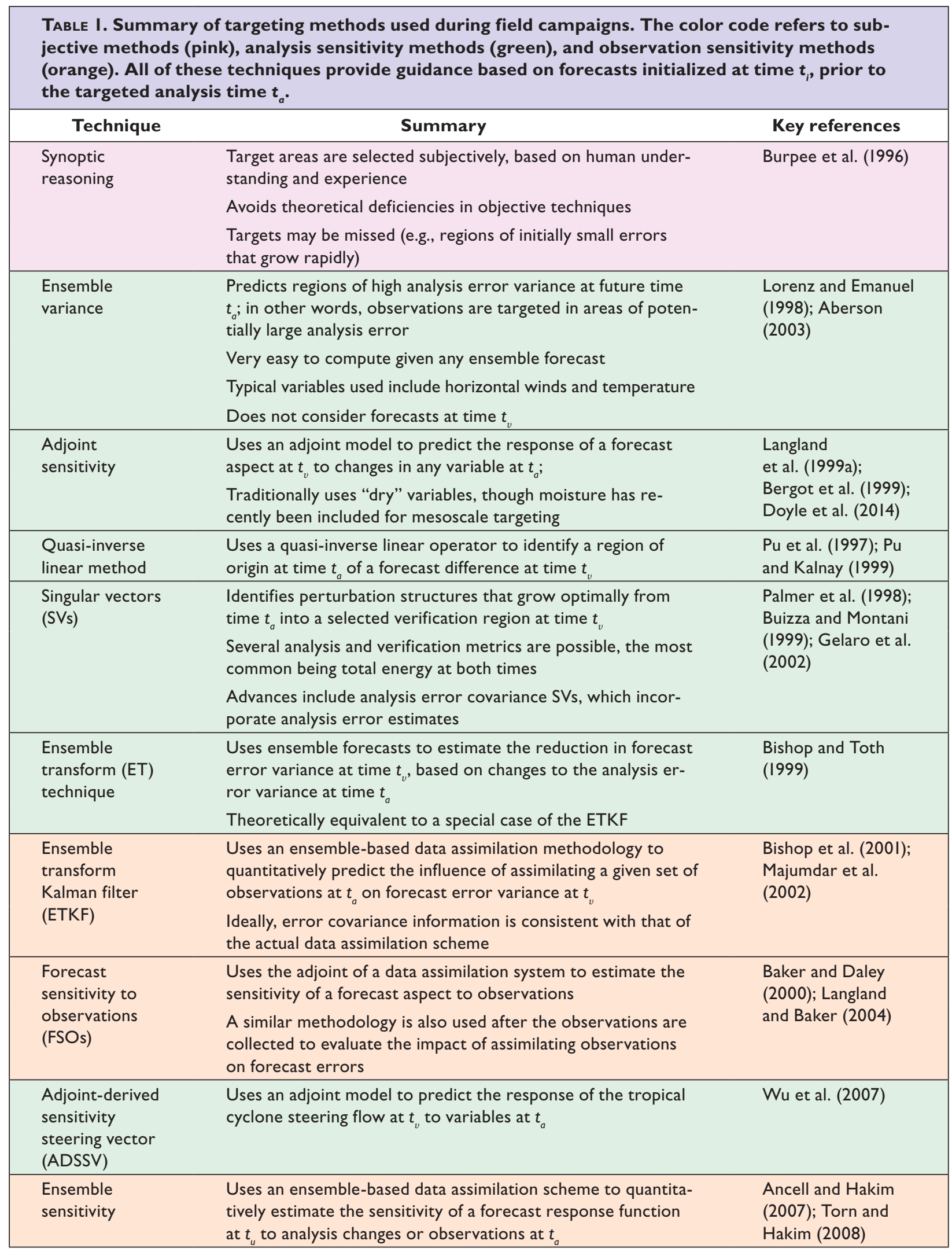


guidance products and accounted for the constraints of the aircraft. Second, while all the techniques possess limitations, they have mostly demonstrated the ability to provide reliable guidance under operational time constraints, and they show potential in predicting the impact of assimilating observations on selected forecasts. However, some crucial practical issues exist, such as whether the observations sample the full extent of the target areas, and whether the assimilation scheme and model are able to cleanly translate improved analyses within the target areas into better forecasts.

FIELD CAMPAIGNS. Around 20 field campaigns have included a component in which observations were targeted to improve predictions of a weather event. Additionally, a handful of relevant studies that did not involve a field campaign have been performed. A chronology of the field campaigns is provided in Table 2, together with a summary of their goals, instrumentation, the targeting guidance products used, evaluation results, and key publications. Many further publications that focus on the field campaigns are listed in the supplemental online bibliography (labeled with an F). The goals and new developments associated with the major experiments together with lessons learned are summarized in this section.

Pre-THORPEX. The establishment of NOAA's Hurricane Synoptic Flow experiments between 1982 and 1996 was driven by the need to improve forecasts of TC track. Dropwindsonde observations were targeted in the synoptic environment of the TC to augment the satellite data that were assimilated into numerical models. The success of these early experiments led to NOAA establishing an annual operational "synoptic surveillance" program in 1997 with a dedicated new aircraft, the Gulfstream IV (G-IV) jet. The goal of this program has been to release dropwindsondes in critical areas, in order for $12-60$-h forecasts to inherit the benefits from the data prior to and during the issuance of watches and warnings. This program also motivated the initiation of Taiwan's annual Dropsonde Observations for Typhoon Surveillance near the Taiwan Region (DOTSTAR) program in 2003. The consensus view is that TC surveillance is practicable operationally, and that the benefits of better preparations and responses due to improved forecasts justify the costs. A side benefit is that many published studies have resulted from the surveillance data.

In the extratropics, the multiple successes of FASTEX followed by the more focused North Pacific Experiment (NORPEX) experiment, which coincided with an El Niño event in early 1998, led to NOAA establishing the annual Winter Storm Reconnaissance (WSR) program in 1999. The objective of WSR was to deploy targeted dropwindsondes over the northern Pacific Ocean to improve 1-5-day forecasts of events over the United States. Forecasters from the National Weather Service selected events of interest each day such as a potential snowstorm, assigned a priority to each event, and made the call on where to deploy the aircraft (if at all). The smooth implementation of WSR demonstrated the practicability of an operational end-to-end system that efficiently combined human decision-making with automated components such as the targeting guidance and subsequent flight track selection. The collection of data from over 5000 dropwindsondes through the duration of WSR (1999-2013) provided a large sample of high quality observations relevant to developing storms over the Pacific Ocean. Although these data could be utilized for a variety of studies, their actual use beyond a small number of targeting papers appears to be limited.

The THORPEX era. The Atlantic Observing-System Research and Predictability Experiment (THORPEX) Regional Campaign (A-TReC) in 2003, sponsored by the European Meteorological Network (EUMETNET) Composite Observing System (EUCOS), was the first extratropical field campaign over the northern Atlantic Ocean to employ targeted observations since FASTEX. Its goal was to test the feasibility of quasi-operational targeting with a large variety of in situ and remotely sensed observational data. More refined versions of the targeting techniques were used, including SVs with norms based on analysis errors, adjoint models that included moisture, observation sensitivity, and an upgraded ETKF. In 2006, a THORPEX component of the African Monsoon Multidisciplinary Analyses (AMMA) was aimed at improving forecasts of African rainfall and easterly waves that may lead to tropical cyclogenesis. An innovation was the "driftsonde" (Drobinski et al. 2013), comprising a large stratospheric balloon and gondola carrying up to 40 dropwindsondes, which could be released on command in a target region. The driftsonde was also employed during Concordiasi in 2010, as part of the THORPEX International Polar Year efforts. These campaigns all demonstrated the successful large-scale coordination of a variety of observing platforms between several nations.

In the mid-2000s, a EUCOS study suggested that the degradation of the ground-based observational network would have a significant negative impact on the forecast skill. This paved the way for the 


\begin{tabular}{|c|c|c|c|c|c|c|c|c|c|c|}
\hline 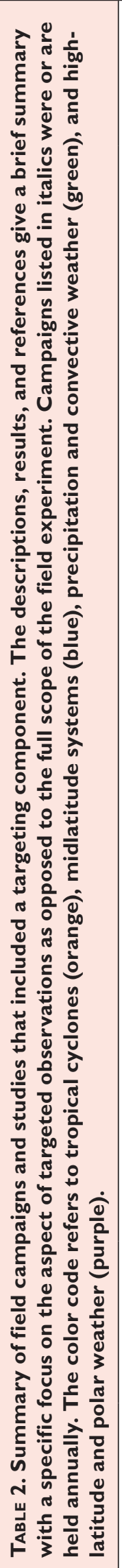 & 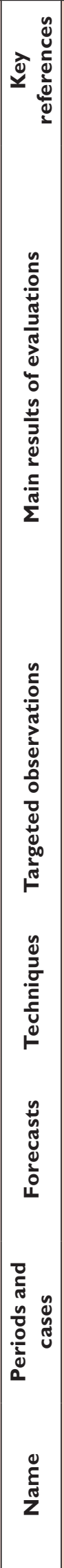 & 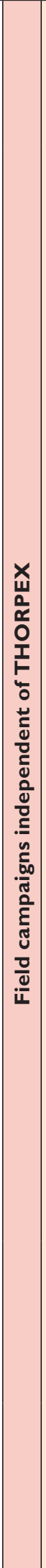 & 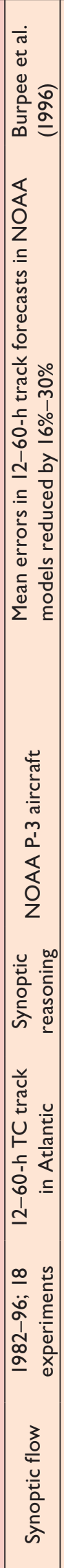 & 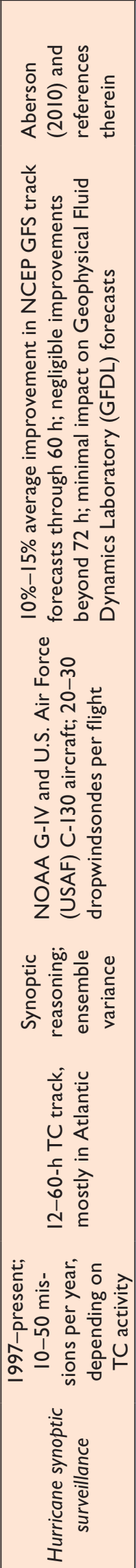 & 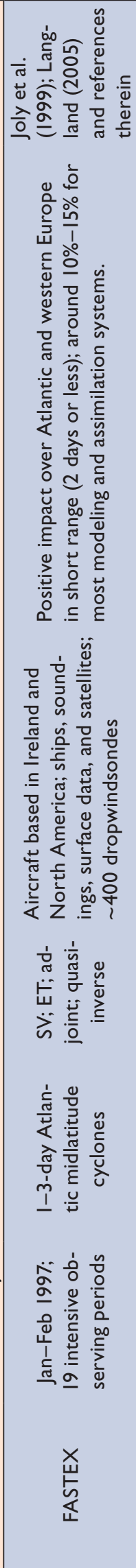 & 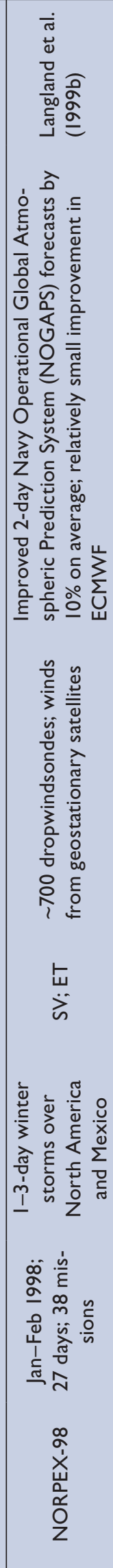 & 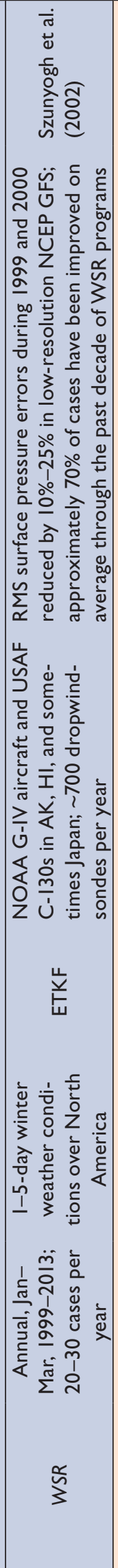 & 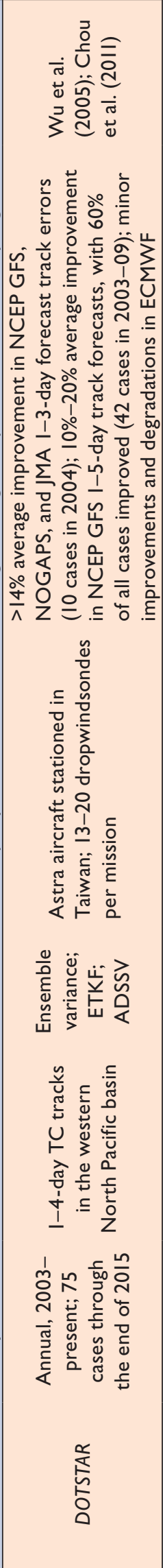 & 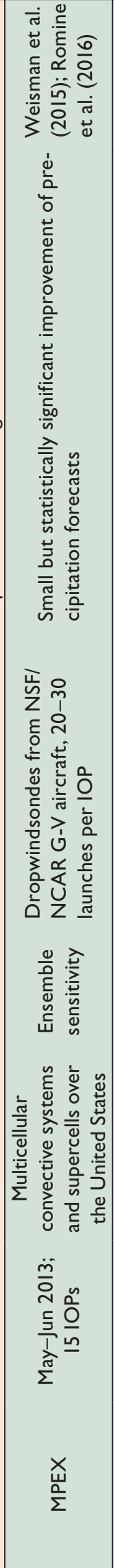 & 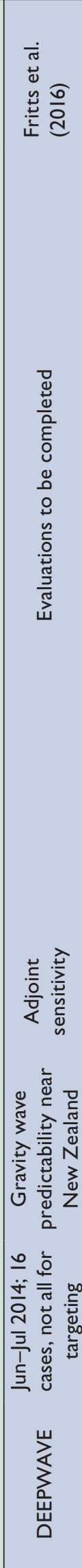 \\
\hline
\end{tabular}




\begin{tabular}{|c|c|c|c|c|c|c|c|c|}
\hline & 离 & & & 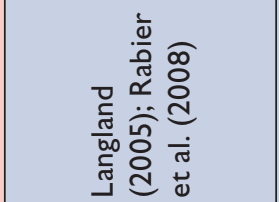 & 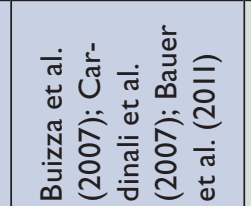 & 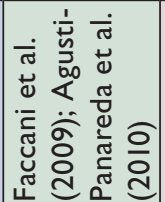 & 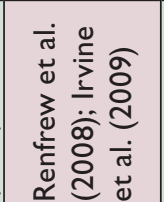 & 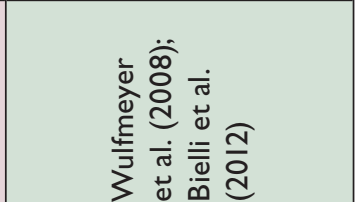 \\
\hline & 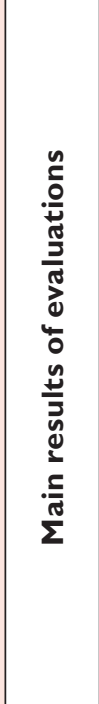 & 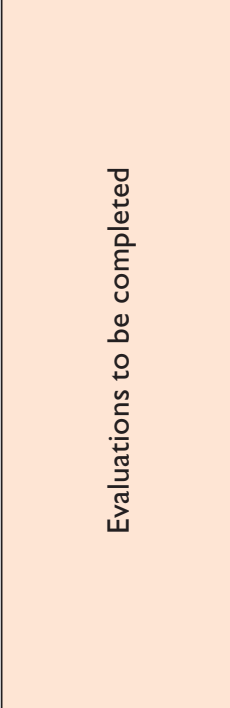 & 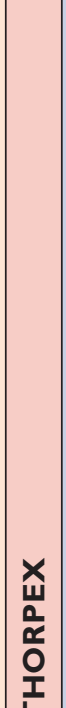 & 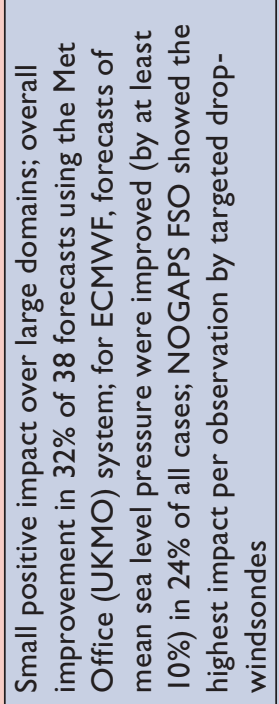 & 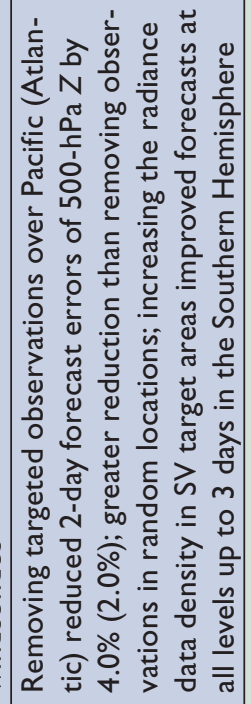 & 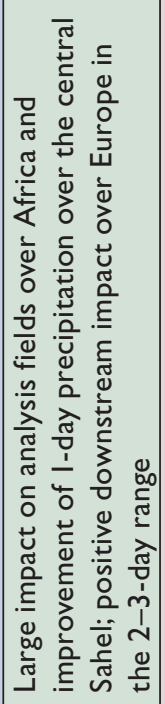 & 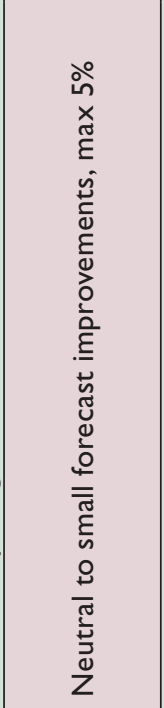 & 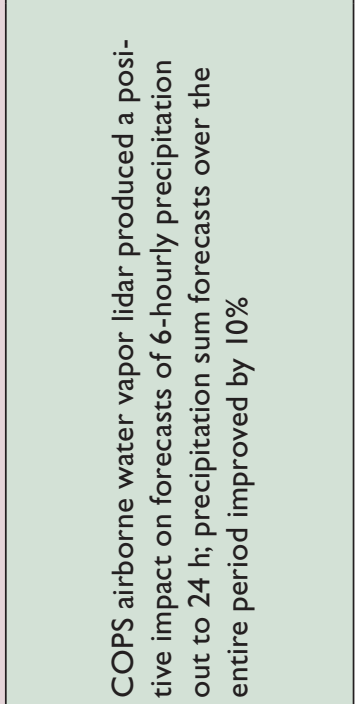 \\
\hline & 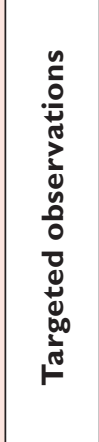 & 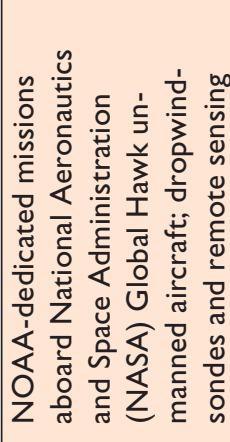 & 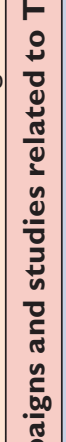 & 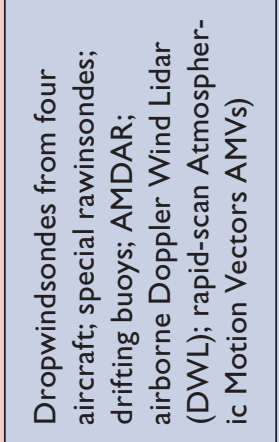 & 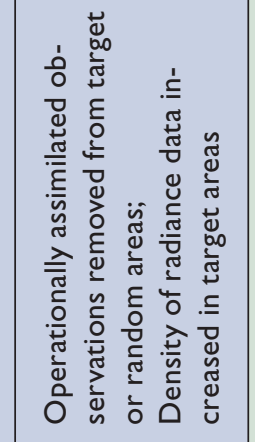 & 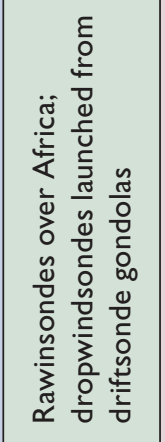 & 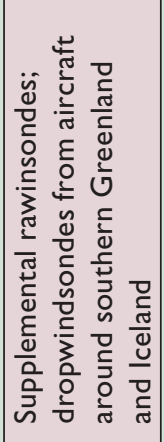 & 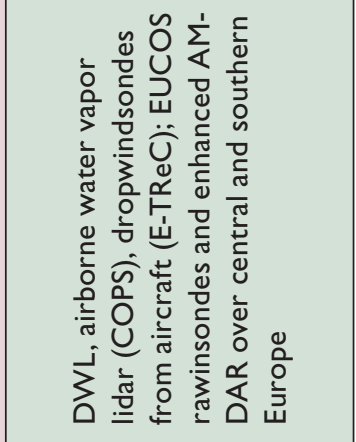 \\
\hline & 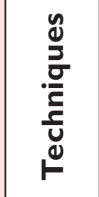 & 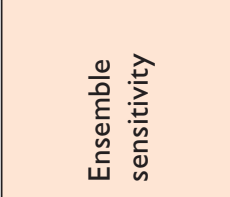 & 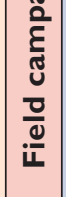 & 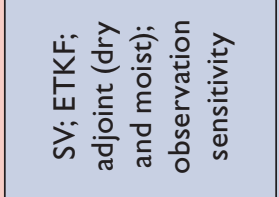 & ¿ & 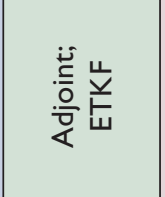 & 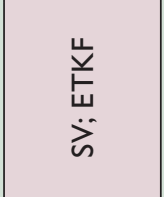 & 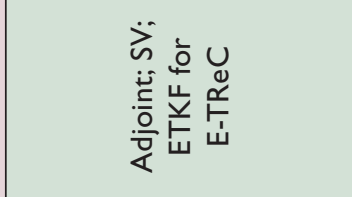 \\
\hline & 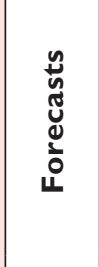 & 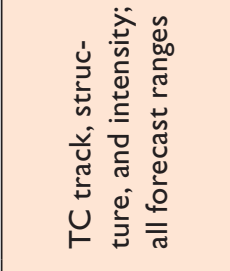 & & 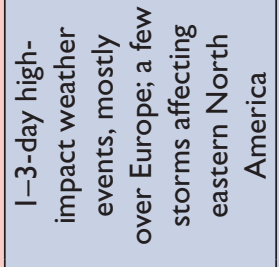 & 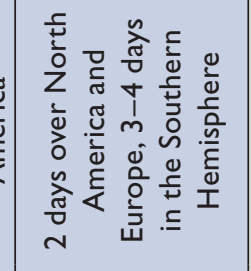 & 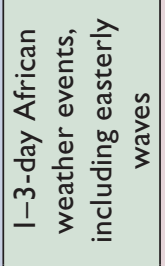 & 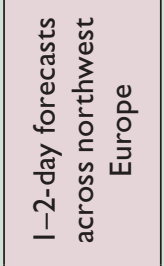 & 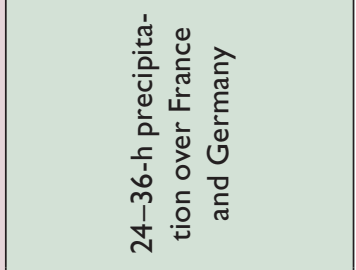 \\
\hline$\stackrel{d}{\square}$ & 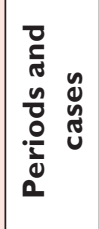 & 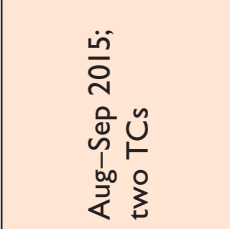 & & 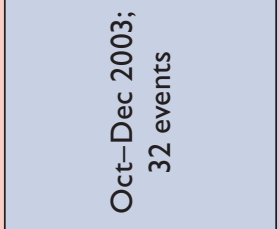 & 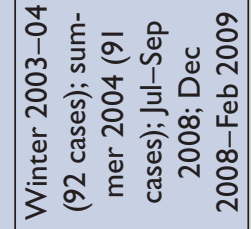 & 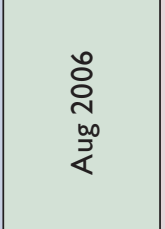 & 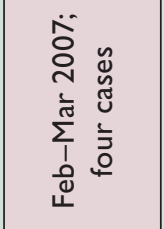 & 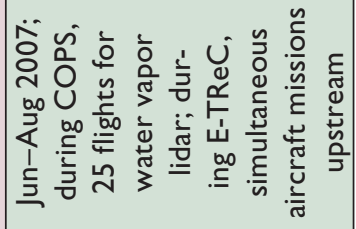 \\
\hline . & $\begin{array}{l}\text { Еू } \\
\text { Zू }\end{array}$ & $\begin{array}{l}5 \\
\frac{5}{1} \\
\text { I }\end{array}$ & & 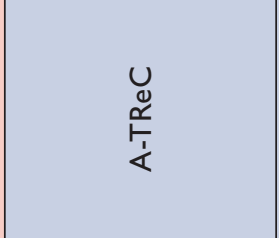 & 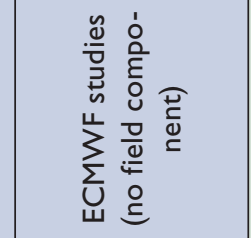 & 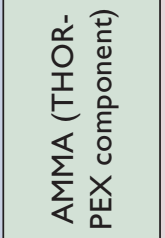 & 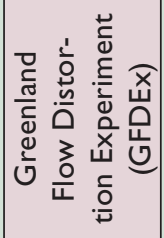 & 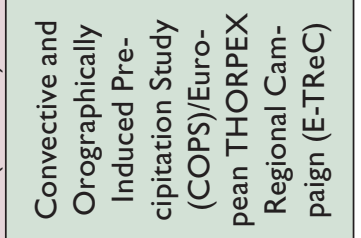 \\
\hline
\end{tabular}




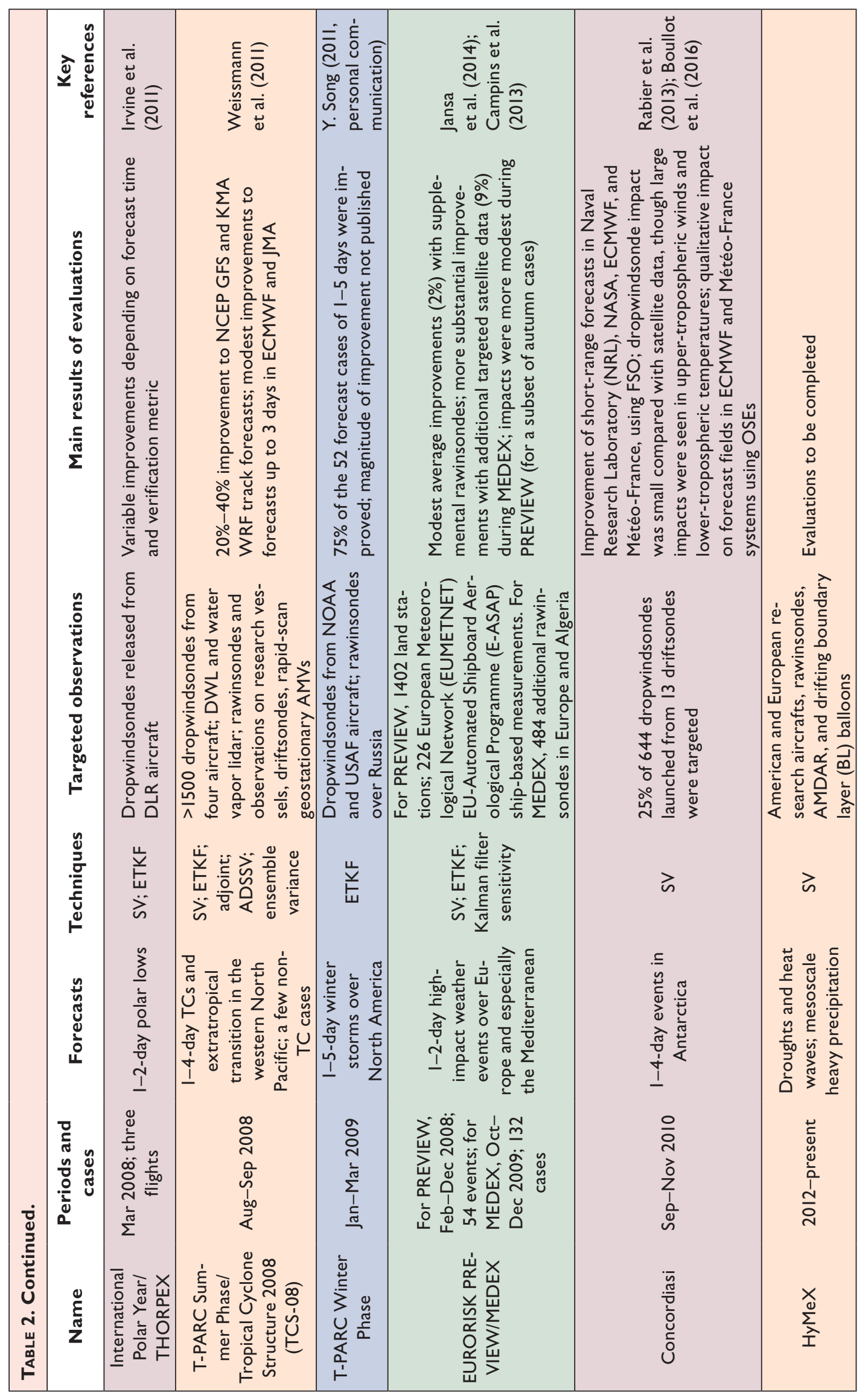


establishment of an adaptively controlled operational observing system in Europe, with increased flexibility in the land-based rawinsonde network plus in situ components such as Aircraft Meteorological Data Relay (AMDAR) and rawinsondes from merchant ships. To coordinate requests for multiple types of targeted observations during field operations, the EURORISK PREVIEW Data Targeting System (DTS) was established. The web-based facility allows registered users to identify potential high-impact weather events, request sensitive area calculations for chosen cases, identify and issue requests for targeted observations, and monitor the requested observations. Successful examples of the use of the PREVIEW DTS were during the Mediterranean Experiment (MEDEX) and the THORPEX Pacific Asian Regional Campaign (T-PARC).

T-PARC possessed an ambitious scope. The summer phase in 2008 was aimed at investigating the science and predictability of the life cycle of TCs in the western North Pacific basin, from formation through to recurvature and extratropical transition, including tropical-extratropical interactions and the flow far downstream in the midlatitude storm track. As had been the case for FASTEX, this campaign stood out because of the remarkable number of international collaborations and publications generated, ranging from predictability and processes through to targeting methods and evaluations (Parsons et al. 2017). The winter phase in early 2009 was aimed at targeting observations to improve forecasts out to a week over North America. During both phases, the PREVIEW DTS facilitated the comparison between different targeting guidance products and improved the efficiency of the decision-making process for multiple observation types.

Given the increased emphasis on mesoscale prediction in the community in the 2010s, several field campaigns have followed suit. Examples include the Hydrological Cycle in the Mediterranean Experiment (HyMeX), the Mesoscale Predictability Experiment (MPEX), and the Deep Propagating Gravity Wave Experiment (DEEPWAVE) in Europe, the United States, and New Zealand, respectively.

Targeted observations have also been tested in the ocean, using mobile platforms such as underwater gliders (Curtin and Bellingham 2009). These programs served to initiate collaborations across multiple disciplines (e.g., physical and biological oceanography) that may not otherwise have occurred, as well as coordinating multiple types of underwater vehicles, and establishing new data sharing and formatting protocols.
Overall, much has been developed and learned through the implementation of these field campaigns, which took place across six continents (Europe, Asia, Africa, Australasia, Antarctica, and North America). There were several programmatic successes: i) an adaptively controlled data targeting system could be run smoothly; ii) new targeting techniques were developed and employed in real time; iii) existing instrumentation was adapted and new instrumentation was tested; iv) long-term multinational collaborations were established; v) students and scientists in dynamics, data assimilation, and modeling were brought together with forecasters and exposed to operational models; and vi) databases of observations, targeting guidance, and model outputs were created and shared. Challenges included suboptimal sampling due to the limited range of the aircraft, and the need to rely on guidance initialized over 2 days prior to $t_{a}$ because of the lead time required for deployment. What has yet to be determined in this paper is whether the targeted observations improved the forecasts, and that is the topic of the next section. A discussion of how the targeted observations are evaluated is also provided in the second sidebar.

RESULTS FROM EVALUATIONS. At the conclusion of a field campaign, operational and research teams usually perform evaluations of the influence of targeted observations on numerical forecasts. The general results for each field campaign, together with a key reference, are summarized in Table 2, with many more references on evaluations available in the online bibliography (labeled with an E). The results are difficult to interpret or generalize in many situations. A net improvement using one variable for evaluation (e.g., 500-hPa geopotential height) does not imply that another variable (e.g., precipitation) will be improved. Furthermore, the results may be sensitive to the sample of cases, the room for improvement in the sample, the forecast window $\left(t_{v}-t_{a}\right)$, the model and data assimilation scheme, and the choice of verification region. The following subsections are organized by common themes.

Field campaigns in the extratropics. To evaluate the impact of assimilating the FASTEX targeted observations, several groups associated with major operational centers performed Observing System Experiments (OSEs) in the late 1990s. While the results varied by center, the average improvements of the forecast events in global models were found to be around $10 \%-15 \%$. Importantly, it was suggested by Bergot (1999) that the results depend substantially on the 
data assimilation scheme, a notion that is now widely accepted. Similar results were found for NORPEX. The early evaluations of WSR found improvements to low-resolution National Centers for Environmental Prediction (NCEP) Global Forecast System (GFS) forecasts within the verification regions in around $70 \%$ of all cases, with an average magnitude that was considered equivalent to a 12 -h gain in forecast lead time. Forecasts of sea level pressure and total energy were used, though precipitation forecasts were not verified. No evaluations were published for the 2002-10 WSR programs, though NCEP suggested that the same proportions of forecasts were improved with an average improvement of $10 \%-20 \%$ for cases selected as a high priority (Y. Song 2011, personal communication). Recent studies in the United States and Europe found that the influence of assimilating WSR data, using the latest assimilation systems, was negligibly small (Hamill et al. 2013). These conclusions led to NOAA suspending the WSR program from 2014, though occasional missions are still requested.

The targeted WSR data were usually collected in features such as upper-tropospheric waves and mature cyclones. Such areas are often cloudy, limiting the influence of satellite data and suggesting the need for detailed in situ sampling of the vertical structure. Generally, the assimilation of observations sampled within the selected target regions produced a larger improvement in the forecasts than those outside the target regions, even if the overall magnitude of the improvement was often small. The propagation of the effect of the targeted observations was found to be associated with processes such as downstream baroclinic development (Szunyogh et al. 2002).

At least six centers used OSEs to evaluate the influence of assimilating the targeted A-TReC data. Unlike FASTEX, the targeted data made little difference to the forecasts, owing to the forecasts over Europe being largely accurate without the targeted observations. These neutral results were corroborated by studies using the forecast sensitivity to observations (FSO) method in which small improvements were found, even though the A-TReC dropwindsondes had been deployed in an area of relatively high sensitivity to observations. Langland (2005) suggested that improvements to regular analyses and forecasts due to "substantial increases in the amounts of regular observations from aircraft and satellites" during the 6-yr interval between FASTEX and A-TReC led to a reduction in the potential impact from the targeted observations. Evaluations from the next large extratropical THORPEX campaign, the winter phase of T-PARC in 2009, remain unpublished.
For Concordiasi, OSEs and FSO studies show qualitative and quantitative positive impacts per dropwindsonde, especially for lower-tropospheric temperature (where radiance data are less reliable) and upper-tropospheric wind. It was suggested that these improvements were in areas of high instability (seen in the targeted SVs) and low data coverage. In smaller extratropical campaigns, the few evaluations provided results that were interesting on a case-bycase basis, though without decisive conclusions.

The key lessons learned from targeting in the extratropics is that the magnitudes of the forecast improvements, while largely positive, are usually small and difficult to interpret scientifically and in terms of socioeconomic value. This could be for several reasons. In many cases, the forecast errors were small even without the targeted observations, leaving minimal room for improvement. This suggests the need for a technique that quantitatively predicts the error evolution prior to deployment, to identify cases in which targeted observations would likely be redundant. Several targeting methods, together with estimates of forecast uncertainty based on the ensemble variance, provide a framework for making such estimates. Additionally, given the lack of in-depth evaluations, a clear scientific understanding of how the data assimilation scheme is using the targeted data to improve the analysis, and the subsequent propagation of this improvement for future forecasts, remains elusive. The inability to sample the synoptic-scale extent of the target regions with aircraft also suggests that other types of targeted data with a broader range and frequency of coverage would be useful.

Field campaigns in the tropics. Evaluations of targeted observations aimed at improving TC track forecasts have almost entirely been conducted using OSEs. In NOAA's early Hurricane Synoptic Flow experiments, the average track forecast improvements from the dropwindsonde data were very large (30\%). During the first decade of synoptic surveillance (1997-2006) the NCEP GFS track forecasts were improved, though by a smaller amount $(10 \%-15 \%)$. Similar improvements were found in the GFS for TCs worldwide during an active 6-week period in 2008 in which NOAA missions in the Atlantic and T-PARC missions in the western North Pacific took place [10\%; Aberson (2011)]. Results from DOTSTAR have shown similar improvements to TC track forecasts. Individual case studies in the 2010s have shown a modest positive impact on the track forecasts.

A key multi-agency paper from T-PARC illustrated the dependence on the modeling and assimilation 
$\mathrm{T}_{\mathrm{s}}^{\mathrm{h}}$ he most widely used method for observation evaluation is OSE. First, a "control" assimilation-forecast cycle is run through the period of interest with all operationally assimilated observations. Next, a parallel cycle, which is identical to the control except that the dataset in question is either added to or withheld from the assimilation, is run. The difference between the two forecasts integrated from analyses valid at the same time in the two cycles is the "data impact." The improvement in the forecast is defined as the difference between the errors of the two forecasts, evaluated against either observations or a verifying analysis within the verification region. In some studies, a small mobile verification region centered on the event is chosen. In other studies, larger fixed regions are used to increase the level of automation and the number of observations available for verification, though the dilution of the verification statistics by areas not associated with the event may result in a weak average impact of the targeted data. OSEs are standard in preoperational testing of new data types and have been used in all targeted observing campaigns. They are limited in that they are computationally expensive, particularly if one wishes to test different components of the datasets.

The more recently developed forecast sensitivity to observations (FSO) method uses the adjoint of a data assimilation system to estimate the contribution of any subset of observations to the reduction in forecast error (Langland and Baker 2004). This technique is more efficient than the OSE and offers the capability to compute the impact on the forecast for any selected data type, location, or channel. While FSO does not quantitatively reproduce the results of an OSE, it has been demonstrated to yield qualitatively similar results. Several operational centers now use the FSO method to monitor the global observing system and the impacts on their models (Gelaro et al. 2010). However, this approach is limited by the tangent linear assumption and so is restricted to short-range forecasts. Recently, ensemble-based FSO methods have been developed and used.

The OSE and FSO methods complement each other, with each method providing unique and helpful information about the impact of observations. system (Weissmann et al. 2011). NCEP and the Korea Meteorological Administration (KMA), who used a three-dimensional variational data assimilation (3DVAR) scheme, showed a large average improvement $(20 \%-40 \%)$ in their $1-5$-day track forecasts due to the targeted dropwindsonde data. In contrast, the European Centre for Medium-Range Weather Forecasts (ECMWF) and the Japan Meteorological Agency (JMA), who employed a four-dimensional variational data assimilation scheme, showed a lower improvement for the same sample, due in part to the forecasts without the targeted data having lower errors and leaving less room for improvement. The same paper also investigated tropical influences on midlatitude forecast skill and predictability using targeted T-PARC data. The 4-5-day cycled ECMWF forecasts of 500-hPa geopotential height in the midlatitudes were found to improve modestly because of the dropwindsonde observations around two TCs. This was attributed to the aforementioned improvements in the corresponding TC track forecasts, which subsequently improved the long-wave pattern downstream.

Extending beyond the limited spatial and temporal coverage of aircraft data, a few studies have been conducted on the influence of assimilating extra satellite data. The benefits to forecasts of TC track and structure of assimilating specially processed rapidscan atmospheric motion vectors were demonstrated during T-PARC (Berger et al. 2011). Further OSEs demonstrated that extra satellite data in SV target regions provided a consistent positive improvement to ECMWF TC track forecasts (Reynolds et al. 2013).

Given recent improvements in models and data assimilation schemes, as well as substantial efforts to advance regional, convection-permitting models, attention is being directed at predictions of TC structure and intensity. While not "targeted" with objective techniques, recent studies have demonstrated the positive impact of assimilating observations such as airborne Doppler radar in the TC inner core (e.g., Zhang and Weng 2015).

For other tropical weather, evaluations are limited beyond the AMMA studies cited in Table 2.

The main conclusion in the evaluations of TC track forecasts is that the targeted observations have on average improved forecasts by around $10 \%$ during the THORPEX era, though the results depend on the model and assimilation system. Although evaluations in the 2010s are limited, the continuation of the aircraft surveillance programs suggests that improvements to track forecasts of around $10 \%$ are sufficient to justify the need for targeted observations. Several of the lessons learned within the context of targeting for extratropical weather are also appropriate here, such as the need to discriminate between scenarios of high versus low room for forecast improvement, a need to understand scientifically and predict how the impact of the targeted observations is propagated forward, and the importance of sampling the extent of the target regions. 
Mesoscale weather. The results from the MEDEX phases in 2008 and 2009 were encouraging. The targeted rawinsondes, which were often deployed upstream of the weather events, improved regional model forecasts of most parameters in the Mediterranean, including precipitation. Crucially, the improvements were found to depend upon the predictability of the forecast case. Targeted satellite data often provided additional improvements.

Results from 15 aircraft missions during MPEX, in which dropwindsondes were spaced about $150 \mathrm{~km}$ apart, found an overall small and positive impact from the targeted data (Romine et al. 2016). These results were consistent with the earlier synoptic-scale evaluations and also possess substantial case-to-case variability.

It is worth emphasizing that a wide variety of assimilation studies using finescale models and observations of high spatial and temporal resolution have been conducted in the past decade. Observations include radars and wind profilers, aimed at improving local, short-range forecasts of severe weather. Although targeting with objective guidance has not been used in these studies, similar concepts can be extended for use.

Targeting of routinely available data. Evaluations of targeted observations have also been done independently of field campaigns, including a series of OSEs conducted by the ECMWF. Buizza et al. (2007) demonstrated that observations in SV target areas reduced the errors in verification regions by a greater amount than observations in randomly selected areas. Furthermore, the impact of the targeted observations was found to be dependent on the region, season, baseline observing system, and flow regime. Bauer et al. (2011) asked the important question of whether additional routine data that are thinned in operations add value to forecasts. They found that if the densities of radiance data in SV target areas were increased, ECMWF forecasts up to 3 days were improved in the Southern Hemisphere.

The FSO method facilitates the comparison of specific observation types. The impacts of major observation types on 24-h forecast errors were found to be similar in different global modeling systems, though regional details varied. The largest error reductions were due to the assimilation of satellite radiances, geostationary satellite winds, rawinsondes, and commercial aircraft. A conclusion across the different modeling systems was that only a small majority $(50 \%-54 \%)$ of the total observations assimilated improved the forecast (Gelaro et al. 2010). Most of the improvement resulted from a large number of observations that had relatively small impacts per observation. This finding amplifies the need to optimize the use of satellite data, and that regional targeting on a continuous basis may be more effective than occasional, limited-area sampling.

Targeting of new observational data. In the majority of field experiments, rawinsondes and dropwindsondes were the primary types of targeted observations. However, one of the goals of THORPEX had been to explore the utility of new observation types. In the THORPEX Implementation Plan, ${ }^{3}$ new in situ sensors considered for targeting included stratospheric balloons, piloted and unmanned aircraft, rocketsondes, and bidirectional radiosondes. The last two were not developed, perhaps because of technological and financial challenges. The vision of targeting with unmanned aircraft is only beginning to be realized 10 years later [e.g., NOAA's Sensing Hazards with Operational Unmanned Technology (SHOUT) program, which began in 2015]. Two other new types of observing platform have been developed, tested, and evaluated. The first is the driftsonde balloon, whose ability to release dropwindsondes in selected regions offers a new observational capability over the oceans without the need for aircraft. Results from evaluations remain very limited. The second is an airborne Doppler wind lidar. During A-TReC, the mean 2-4-day ECMWF forecast errors in 500-hPa geopotential height over Europe were reduced by $3 \%$ as a result of the assimilation of around 1600 wind profiles (Weissmann and Cardinali 2007). During T-PARC, the 1-5-day ECMWF TC track forecast errors were reduced by $50 \mathrm{~km}$ through the cumulative assimilation of 2500 wind profiles (Weissmann et al. 2012). Additional new observation types may be beneficial in the future, though structured studies to investigate their potential prior to deployment may be more cost effective and yield greater forecast benefits.

CONCLUSIONS AND DISCUSSION. The encouraging results in the 1990s led to optimism that targeted observations would benefit forecasts to the extent that adaptive networks would regularly supplement the global observational structure. Accordingly, a series of field campaigns and projects were initiated prior to and during the THORPEX era (2005-14), with observations targeted to improve 1-5-day global model forecasts of high-impact weather events. The PREVIEW DTS and aircraft surveillance programs

\footnotetext{
3 The THORPEX Implementation Plan, published by WMO in 2005, is available at www.wmo.int/pages/prog/arep/wwrp /new/documents/CD_ROM_implementation_plan_vl.pdf.
} 
impressively demonstrated how segments of the available observing network can be coordinated across multiple nations and made adaptable on a daily basis. Evaluations in the extratropics found that the influence of assimilating targeted observations was positive though small. In the tropics, the targeted observations usually improved TC track forecasts, though evaluations in the 2010s are lacking. In the multiagency collaborative OSE studies, the conclusions were found to depend on the model, the data assimilation scheme, and the treatment of the observations. In FSO studies, the impact per targeted observation was found to be high, but their cumulative benefit was small given the vast quantity of routine observations.

The fact that many results are inconclusive is not surprising, for several reasons. First, synoptic-scale NWP is maturing. Advances in the Global Observing System, the improved use of observations by advanced data assimilation schemes, and better model physics and resolution are raising the bar for forecast improvement. As the forecast skill increases, the average marginal impact of any individual observing system decreases. Second, the limited range of in situ observations restricts the data coverage to a fraction of the size of typical target regions, suggesting the need to consider the targeting of more broadly available observations such as satellite radiances. Third, the results depend on the flow regime and may vary beyond the limited samples tested during the field experiments or evaluation studies. The large number of cases in which forecast errors are low without the targeted data suggests that low-predictability cases with substantial room for improvement via targeted observations are not common. Additionally, it is possible in some situations that errors in the model tend to obfuscate the positive improvements to the initial conditions. Fourth, the results can be inconclusive as a result of inconsistencies in the evaluation methods and ambiguity in the perceived value of the verification metric. As an example, the most conclusive results to date have been related to TC track, whose forecast improvement is relatively straightforward to appreciate in terms of socioeconomic gain. On the other hand, an "average $4 \%$ improvement" using an area-averaged norm of an atmospheric variable does not inform the decision-maker about whether the targeted data are cost effective. Finally, the coordination of evaluations across multiple centers with common metrics is challenging, given the different priorities of each agency and the labor and computational expenses of OSEs. It should be noted that one of the most significant successes was a multiagency coordination of FSO studies.
The types of instrumentation used for targeted observations have mostly been supplemental rawinsondes and aircraft-borne dropwindsondes, whose coverage is limited. Some of the new observation platforms proposed at the start of the THORPEX era were developed and put into action (e.g., the driftsonde), whereas others did not materialize (e.g., the bidirectional radiosonde). It remains an open question as to which new platforms would be most useful and cost effective for targeting using the next generation of numerical weather prediction systems. Within the context of short-range, high-resolution forecasts of weather hazards, platforms such as small unmanned aircraft may be useful. However, many technical, financial, and logistical challenges are faced in the development of more comprehensive platforms that can be deployed to important areas (e.g., to sample lower-tropospheric profiles of wind and moisture to capture convective initiation). Within the context of satellite observations, there have been very few studies on how to optimize the use of routinely available data, despite the promising results of Bauer et al. (2011). OSE and FSO studies can be conducted to address this issue. Additionally, new developments such as cost-effective constellations of microsatellites (e.g., Ruf et al. 2016) require investigation. Observing system simulation experiments (OSSEs; Hoffman and Atlas 2016) can be utilized to address questions concerning future observing systems prior to their development or launch. Combining OSSEs with predictability studies, a strategic plan can be designed to prioritize platforms for routine and targeted observations that can provide the largest improvements to societally relevant forecasts.

The objective techniques used to identify preferred locations for targeted observations have been shown to be superior to selecting targets subjectively or randomly. The techniques are likely not the first-order problem, though there is room for improvement, such as in the treatment of nonlinearities, incorporating error characteristics from the data assimilation scheme, and quantitatively predicting the potential forecast impact in order to decide whether substantial forecast gains can be achievable.

The effectiveness of targeted observations depends on the data assimilation scheme, as has been reported in several publications since FASTEX. During the THORPEX era, important advances have been made in variational and ensemble-based data assimilation, as reported in Parsons et al. (2017). As data assimilation schemes advance, so do the impacts of assimilating observations. In this changing landscape, in which forecast models and the observational network are also advancing, the results from the THORPEX era (e.g., 
those that used 3DVAR) may not be directly relevant to planning over the next decade. It is also an interesting question whether improvements in data assimilation will render targeted observations more or less useful. One can argue that there is less room for improvement if the superior assimilation of routine observations yields smaller analysis and forecast errors. On the other hand, one can also argue that an improved data assimilation scheme is able to better exploit the targeted data, spreading their influence within regions in which analysis errors may be large or may grow quickly.

The relationship between forecast improvements found by the evaluation studies and the corresponding socioeconomic values is largely unknown (though it is more tangible for TC tracks). Research designed to quantify the benefits would help sharpen the development and usage of observing systems. Furthermore, forecast improvement has commonly been quantified for deterministic forecasts. Given the increased emphasis of ensemble forecasts as part of an integrated forecasting system, the impact of targeted observations on narrowing the forecast uncertainty and improving the probability density function would be another avenue for investigation.

In summary, the initial vision that the Global Observing System would ultimately be supplemented by networks on an adaptive basis, or even optimized into a fully adaptive network, has not been realized. In 2016, the only targeted observations deployed operationally are for TC surveillance. The proliferation of studies has slowed down, as is evident in the bibliography included in the online supplement to this paper. Nevertheless, the author believes that the concept of targeting observations to improve forecasts of high-impact weather events remains useful, even though a compelling justification is elusive. Several ideas from over a decade ago, such as the assimilation of targeted satellite data (Langland 2005) remain relevant. However, one constraint is that targeted observational networks are expensive and time consuming to design. A strong justification is also needed to propose an alteration to an operational NWP system to automatically assimilate observations in target areas. In light of these conclusions, the author suggests a creative rethinking of the approach taken to accomplish the goal of using targeted observations in a cost-effective manner, using state-of-the-art and future prediction systems. Some recommendations aimed at this goal are provided in the final section.

RECOMMENDATIONS. Based on annual meetings and discussions with the DAOS Working Group, as well as with numerous personnel in the field, several recommendations are made. They are based partially on the conclusions and lessons learned during the field campaigns and studies, and also via the identification of deficiencies that had not been addressed during those field campaigns, along with parallel advances in observations, modeling, and data assimilation.

\section{Optimize use of the global observational network.}

i) Exploit observational resources that are routinely available and potentially adaptable, such as special processing, targeting, and/or thinning of satellite radiances and winds. Facilities such as the PREVIEW DTS can be used for this purpose. Systematic, regime-based targeting can be continuously conducted on a broader scale over days to weeks, especially during low-predictability regimes.

ii) Explore the utility of new observing platforms, such as space-based lidar; high-altitude, long-endurance unmanned aircraft; and surface data such as pressure readings from smart phones. Rapid response and assimilation would be essential.

iii) With an increasing emphasis on small-scale prediction, explore the potential for targeting the use of convective-scale models. Potential observational resources include mobile mesonets for forecasts of severe weather, and airborne Doppler radar and unmanned aircraft for forecasts of tropical cyclone structure and intensity. New techniques for targeting guidance may need to be developed.

\section{Invest in quantitative evaluations and understanding.}

i) Field programs, whether in research or operations, require routine evaluations.

ii) Explore concepts of future targeted observations via OSSEs. The OSSE uses the OSE concept to evaluate the potential impact of assimilating synthetic observations, sampled from a highresolution "nature run," which also serves as the "truth" against which forecasts are evaluated. OSSEs are presently being used to quantify the impact of future satellite observing systems on NWP. They possess strengths and limitations.

iii) Assess the role of the data assimilation scheme, including the treatment of targeted observations versus routinely available observations, and the use of flow-dependent spatial structure functions that control the spread of the influence of the observations.

iv) Quantify the reduction in forecast uncertainty realized by the assimilation of targeted observations, using ensemble-based probabilistic forecasts. 
Assess the value of improved forecasts.

i) Identify the low-predictability regimes in which forecasts are most likely to "bust" because of initial condition errors and, therefore, where targeted observations are expected to yield the highest benefit. Identify priorities for phenomena whose prediction requires improvement. In parallel, improve the basis for quantitatively predicting the influence of targeted observations on forecast errors.

ii) Improve our understanding of the socioeconomic impact of assimilating targeted observations, via user-focused measures of the value of forecast improvements.

In closing, considerable progress has been made toward the goal of supplementing the Global Observing System with targeted observations, with enhanced international cooperation fostered through THORPEX. However, many open and fundamental questions remain, most notably the overall cost effectiveness and benefits to society of creating a network on a more adaptive basis. Investments in the collaborative design and evaluation of strategies to target observations are necessary to ensure that modifications to the Global Observing System are of value to society.

ACKNOWLEDGMENTS. The advancement of targeted observations would not have been possible without the financial support from several nations, and the substantial efforts of all involved in the planning, execution, and evaluation of field campaigns and related initiatives. The THORPEX Program Office enabled many of these activities. The author thanks the WMO/WWRP DAOS Working Group for suggesting and reviewing this article. Finally, the comments and criticisms of three anonymous reviewers greatly improved the article.

\section{REFERENCES}

Aberson, S. D., 2003: Targeted observations to improve operational tropical cyclone track forecast guidance. Mon. Wea. Rev., 131, 1613-1628, doi:10.1175//2550.1.

__ 2010: 10 years of hurricane synoptic surveillance (1997-2006). Mon. Wea. Rev., 138, 1536-1549, doi:10.1175/2009MWR3090.1.

— 2011: The impact of dropwindsonde data from the THORPEX-Pacific Area Regional Campaign and the NOAA Hurricane Field Program on tropical cyclone forecasts in the Global Forecasting System. Mon. Wea. Rev., 139, 2689-2703, doi:10.1175/2011MWR3634.1. Agusti-Panareda, A., A. Beljaars, C. Cardinali, I. Genkova, and C. Thorncroft, 2010: Impact of assimilating AMMA soundings on ECMWF analyses and forecasts. Wea. Forecasting, 25, 1142-1160, doi:10.1175 /2010WAF2222370.1.

Ancell, B., and G. J. Hakim, 2007: Comparing adjointand ensemble-sensitivity analysis with applications to observation targeting. Mon. Wea. Rev., 135, 4117-4134, doi:10.1175/2007MWR1904.1.

Baker, N. L., and R. Daley, 2000: Observation and background adjoint sensitivity in the adaptive observation-targeting problem. Quart. J. Roy. Meteor. Soc., 126, 1431-1454, doi:10.1002/qj.49712656511.

Bauer, P., R. Buizza, C. Cardinali, and J.-N. Thépaut, 2011: Impact of singular vector based satellite data thinning on NWP. Quart. J. Roy. Meteor. Soc., 137, 286-302, doi:10.1002/qj.733.

Berger, H., R. Langland, C. S. Velden, C. A. Reynolds, and P. M. Pauley, 2011: Impact of enhanced satellitederived atmospheric motion vector observations on numerical tropical cyclone track forecasts in the western North Pacific during TPARC/TCS-08. J. Appl. Meteor. Climatol., 50, 2309-2318, doi:10.1175 /JAMC-D-11-019.1.

Bergot, T., 1999: Adaptive observations during FASTEX: A systematic survey of upstream flights. Quart. J. Roy. Meteor. Soc., 125, 3271-3298, doi:10.1002 lqj.49712556108.

—_, G. Hello, A. Joly, and S. Malardel, 1999: Adaptive observations: A feasibility study. Mon. Wea. Rev., 127, 743-765, doi:10.1175/1520-0493(1999)127<0743:AO AFS $>2.0 . C O ; 2$.

Bielli, S., M. Grzeschik, E. Richard, C. Flamant, C. Champollion, C. Kiemle, M. Dorninger, and P. Brousseau, 2012: Assimilation of water-vapour airborne lidar observations: Impact study on the COPS precipitation forecasts. Quart. J. Roy. Meteor. Soc., 138, 1652-1667, doi:10.1002/qj.1864.

Bishop, C. H., and Z. Toth, 1999: Ensemble transformation and adaptive observations. J. Atmos. Sci., 56, 1748-1765, doi:10.1175/1520-0469(1999)056<1748:ET $\mathrm{AAO}>2.0 . \mathrm{CO} ; 2$.

_ B. J. Etherton, and S. J. Majumdar, 2001: Adaptive sampling with the ensemble transform Kalman filter. Part I: Theoretical aspects. Mon. Wea. Rev., 129, 420-436, doi:10.1175/1520-0493(2001)129<0420:AS WTET>2.0.CO;2.

Boullot, N., F. Rabier, R. Langland, R. Gelaro, C. Cardinali, V. Guidard, P. Bauer, and A. Doerenbecher, 2016: Observation impact over the southern polar area during the Concordiasi field campaign. Quart. J. Roy. Meteor. Soc., 142, 597-610, doi:10.1002/qj.2470.

Buizza, R., and A. Montani, 1999: Targeted observations using singular vectors. J. Atmos. Sci., 56, 2965-2985, doi:10.1175/1520-0469(1999)056<2965:TOUSV >2 .0.CO;2. 
—, C. Cardinali, G. Kelly, and J.-N. Thépaut, 2007: The value of observations. II: The value of observations located in singular-vector-based target areas. Quart. J. Roy. Meteor. Soc., 133, 1817-1832, doi:10.1002 /qj.149.

Burpee, R. W., J. L. Franklin, S. J. Lord, R. E. Tuleya, and S. D. Aberson, 1996: The impact of Omega dropwindsondes on operational hurricane track forecast models. Bull. Amer. Meteor. Soc., 77, 925-933, doi:10.1175/1520-0477(1996)077<0925:TIOODO $>2.0$.CO;2.

Campins, J., B. Navascués, C. Santos, and A. AmoBaladrón, 2013: Influence of targeted observations on short-term forecasts of high-impact weather events in the Mediterranean. Nat. Hazards Earth Syst. Sci., 13, 2891-2910, doi:10.5194/nhess-13-2891-2013.

Cardinali, C., R. Buizza, G. Kelly, M. Shapiro, and J.N. Thépaut, 2007: The value of observations. III: Influence of weather regimes on targeting. Quart. J. Roy. Meteor. Soc., 133, 1833-1842, doi:10.1002/qj.148.

Chou, K.-H., C.-C. Wu, P.-H. Lin, S. D. Aberson, M. Weissmann, F. Harnisch, and T. Nakazawa, 2011: The impact of dropwindsonde observations on typhoon track forecasts in DOTSTAR and T-PARC. Mon. Wea. Rev., 139, 1728-1743, doi:10.1175/2010MWR3582.1.

Curtin, T. B., and J. G. Bellingham, 2009: Progress toward autonomous ocean sampling networks. DeepSea Res. II, 56, 62-67, doi:10.1016/j.dsr2.2008.09.005.

Doyle, J. D., C. Amerault, C. A. Reynolds, and P. A. Reinecke, 2014: Initial condition sensitivity and predictability of a severe extratropical cyclone using a moist adjoint. Mon. Wea. Rev., 142, 320-342, doi:10.1175/MWR-D-13-00201.1.

Drobinski, P., and Coauthors, 2013: Driftsonde observations to evaluate numerical weather prediction of the late 2006 African monsoon. J. Appl. Meteor. Climatol., 52, 974-995, doi:10.1175/JAMC-D-11-0176.1.

Faccani, C., and Coauthors, 2009: The impact of the AMMA rawinsonde data on the French global assimilation and forecast system. Wea. Forecasting, 24, 1268-1286, doi:10.1175/2009WAF2222237.1.

Fritts, D. E., and Coauthors, 2016: The Deep Propagating Gravity Wave Experiment (DEEPWAVE): An airborne and ground-based exploration of gravity wave propagation and effects from their sources throughout the lower and middle atmosphere. Bull. Amer. Meteor. Soc., 97, 425-453, doi:10.1175/BAMS-D-14-00269.1.

Gelaro, R., T. Rosmond, and R. Daley, 2002: Singular vector calculations with an analysis error variance metric. Quart. J. Roy. Meteor. Soc., 128, 205-228, doi:10.1256/00359000260498860.

—, R. H. Langland, S. Pellerin, and R. Todling, 2010: The THORPEX Observation Impact Intercomparison
Experiment. Mon. Wea. Rev., 138, 4009-4025, doi:10.1175/2010MWR3393.1.

Hamill, T. M., F. Yang, C. Cardinali, and S. J. Majumdar, 2013: Impact of targeted Winter Storm Reconnaissance dropwindsonde data on midlatitude numerical weather predictions. Mon. Wea. Rev., 141, 2058-2065, doi:10.1175/MWR-D-12-00309.1.

Hoffman, R. N., and R. Atlas, 2016: Future observing system simulation experiments. Bull. Amer. Meteor. Soc., 97, 1601-1616, doi:10.1175/BAMS-D-15-00200.1.

Irvine, E. A., S. L. Gray, J. Methven, I. A. Renfrew, K. Bovis, and R. Swinbank, 2009: The impact of targeted observations made during the Greenland Flow Distortion Experiment. Quart. J. Roy. Meteor. Soc., 135, 2012-2029, doi:10.1002/qj.499.

— — - and — 2011: Targeted observations of a polar low in the Norwegian Sea. Quart. J. Roy. Meteor. Soc., 137, 1688-1699, doi:10.1002/qj.914.

Jansa, A., and Coauthors, 2014: MEDEX: A general overview. Nat. Hazards Earth Syst. Sci., 14, 1965-1984, doi:10.5194/nhess-14-1965-2014.

Joly, A., and Coauthors, 1999: Overview of the field phase of the Fronts and Atlantic Storm-Track EXperiment (FASTEX) project. Quart. J. Roy. Meteor. Soc., 125, 3131-3163, doi:10.1002/qj.49712556103.

Langland, R. H., 2005: Issues in targeted observing. Quart. J. Roy. Meteor. Soc., 131, 3409-3425, doi:10.1256 /qj.05.130.

— impact using the NRL atmospheric variational data assimilation adjoint system. Tellus, 56A, 189-201, doi:10.1111/j.1600-0870.2004.00056.x.

—, R. Gelaro, G. D. Rohaly, and M. A. Shapiro, 1999a: Targeted observations in FASTEX: Adjoint-based targeting procedures and data impact experiments in IOPs-17 and 18. Quart. J. Roy. Meteor. Soc., 125, 3241-3270, doi:10.1002/qj.49712556107.

— , and Coauthors, 1999b: The North Pacific Experiment (NORPEX-98): Targeted observations for improved North American weather forecasts. Bull. Amer. Meteor. Soc., 80, 1363-1384, doi:10.1175 /1520-0477(1999)080<1363:TNPENT>2.0.CO;2.

Lorenz, E. N., and K. A. Emanuel, 1998: Optimal sites for supplementary weather observations: Simulation with a small model. J. Atmos. Sci., 55, 399-414, doi:10.1175/1520-0469(1998)055<0399:OSFSWO $>2.0 . \mathrm{CO} ; 2$.

Majumdar, S. J., C. H. Bishop, B. J. Etherton, and Z. Toth, 2002: Adaptive sampling with the ensemble transform Kalman filter. Part II: Field program implementation. Mon. Wea. Rev., 130, 1356-1369, doi:10.1175/1520-0493(2002)130<1356:ASWTET $>2.0 . \mathrm{CO} ; 2$. 
—- and Coauthors, 2011: Targeted observations for improving numerical weather prediction: An overview. WWRP/THORPEX Publ. 15, 37 pp. [Available online at www.wmo.int/pages/prog/arep/wwrp/new /documents/THORPEX_No_15.pdf.]

Palmer, T. N., R. Gelaro, J. Barkmeijer, and R. Buizza, 1998: Singular vectors, metrics, and adaptive observations. J. Atmos. Sci., 55, 633-653, doi:10.1175 /1520-0469(1998)055<0633:SVMAAO>2.0.CO;2.

Parsons, D. B., and Coauthors, 2017: THORPEX research and the science of prediction. Bull. Amer. Meteor. Soc., doi:10.1175/BAMS-D-14-00025.1, in press.

$\mathrm{Pu}, \mathrm{Z}$., and E. Kalnay, 1999: Targeting observations with the quasi-linear inverse and adjoint NCEP global models. Quart. J. Roy. Meteor. Soc., 125, 3329-3338, doi:10.1002/qj.49712556110.

— - _ J. Sela, and I. Szunyogh, 1997: Sensitivity of forecast error to initial conditions with a quasi-inverse linear method. Mon. Wea. Rev., 125, 2479-2503, doi:10.1175 /1520-0493(1997)125<2479:SOFETI>2.0.CO;2.

Rabier, F., and Coauthors, 2008: An update on THORPEX-related research in data assimilation and observing strategies. Nonlinear Processes Geophys., 15, 81-94, doi:10.5194/npg-15-81-2008.

— - and Coauthors, 2013: The Concordiasi field experiment over Antarctica: First results from innovative atmospheric measurements. Bull. Amer. Meteor. Soc., 94, ES17-ES20, doi:10.1175/BAMS-D-12-00005.1.

Renfrew, I. A., and Coauthors, 2008: The Greenland Flow Distortion Experiment. Bull. Amer. Meteor. Soc., 89, 1307-1324, doi:10.1175/2008BAMS2508.1.

Reynolds, C. A., R. H. Langland, P. M. Pauley, and C. Velden, 2013: Tropical cyclone data impact studies: Influence of model bias and synthetic observations. Mon. Wea. Rev., 141, 4373-4394, doi:10.1175 /MWR-D-12-00300.1.

Romine, G. S., C. S. Schwartz, R. D. Torn, and M. L. Weisman, 2016: Impact of assimilating dropsonde observations from MPEX on ensemble forecasts of severe weather events. Mon. Wea. Rev., 144, 37993823, doi:10.1175/MWR-D-15-0407.1.

Ruf, C., and Coauthors, 2016: New ocean winds satellite mission to probe hurricanes and tropical convection. Bull. Amer. Meteor. Soc., 97, 385-395, doi:10.1175 /BAMS-D-14-00218.1.

Shapiro, M. A., and A. J. Thorpe, 2004: THORPEX International Science Plan, version 3. WMO/TD 1246, WWRP/THORPEX Rep. 2, 51 pp. [Available online at www.wmo.int/pages/prog/arep/wwrp/new/documents /CD_ROM_international_science_plan_v3.pdf.]

Snyder, C., 1996: Summary of an informal workshop on adaptive observations and FASTEX. Bull. Amer. Meteor. Soc., 77, 953-961.
Szunyogh, I., Z. Toth, A. Zimin, S. J. Majumdar, and A. Persson, 2002: On the propagation of the effect of targeted observations: The 2000 Winter Storm Reconnaissance program. Mon. Wea. Rev., 130, 1144-1165, doi:10.1175/1520-0493(2002)130<1144:PO TEOT $>2.0 . C O ; 2$.

Torn, R. D., and G. J. Hakim, 2008: Ensemble-based sensitivity analysis. Mon. Wea. Rev., 136, 663-677, doi:10.1175/2007MWR2132.1.

Weisman, M., and Coauthors, 2015: The Mesoscale Predictability Experiment (MPEX). Bull. Amer. Meteor. Soc., 96, 2127-2149, doi:10.1175/BAMS -D-13-00281.1.

Weissmann, M., and C. Cardinali, 2007: Impact of airborne Doppler lidar observations on ECMWF forecasts. Quart. J. Roy. Meteor. Soc., 133, 107-116, doi:10.1002/qj.16.

— - and Coauthors, 2011: The influence of assimilating dropsonde data on typhoon track and midlatitude forecasts. Mon. Wea. Rev., 139, 908-920, doi:10.1175/2010MWR3377.1.

— , R. H. Langland, C. Cardinali, P. M. Pauley, and S. Rahm, 2012: Influence of airborne Doppler wind lidar profiles near Typhoon Sinlaku on ECMWF and NOGAPS forecasts. Quart. J. Roy. Meteor. Soc., 138, 118-130, doi:10.1002/qj.896.

Wu, C.-C., and Coauthors, 2005: Dropwindsonde Observations for Typhoon Surveillance near the Taiwan Region (DOTSTAR): An overview. Bull. Amer. Meteor. Soc., 86, 787-790, doi:10.1175/BAMS-86 $-6-787$.

—, J-H. Chen, P-H. Lin, and K-H. Chou, 2007: Targeted observations of tropical cyclone movement based on the adjoint-derived sensitivity steering vector. J. Atmos. Sci., 64, 2611-2626, doi:10.1175 /JAS3974.1.

— , and Coauthors, 2009: Intercomparison of targeted observation guidance for tropical cyclones in the northwestern Pacific. Mon. Wea. Rev., 137, 2471-2492, doi:10.1175/2009MWR2762.1.

Wulfmeyer, V., and Coauthors, 2008: The Convective and Orographically Induced Precipitation Study: A research and development project of the World Weather Research Program for improving quantitative precipitation forecasting in low-mountain regions. Bull. Amer. Meteor. Soc., 89, 1477-1486, doi:10.1175/2008BAMS2367.1.

Zhang, F., and Y. Weng, 2015: Predicting hurricane intensity and associated hazards: A five-year real-time forecast experiment with assimilation of airborne doppler radar observations. Bull. Amer. Meteor. Soc., 96, 25-32, doi:10.1175/BAMS-D-13-00231.1. 
Hurricane Pioneer:

Memoirs of

Bob Simpson

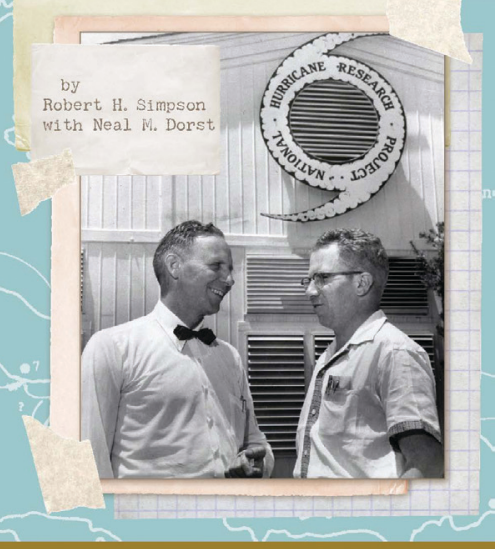

AMERICAN METEOROLOGICAL SOCIETY

Browse online at ametsoc.org/bookstore

FREE SHIPPING for AMS Members!

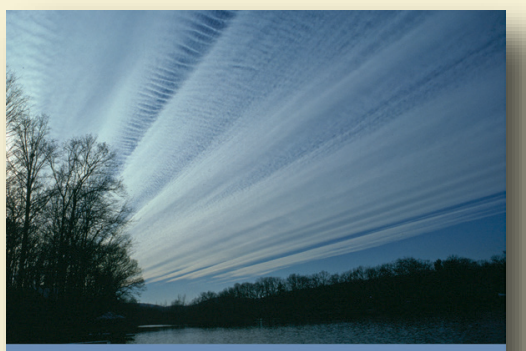

AN OBSERVER'S GUIDE to

CLOUDS AND WEATHER

A NORTHEASTERN PRIMER ON PREDICTION TOBY CARLSON, PAUL KNIGHT, AND CELIA WYCKOFF

\section{HURRICANE PIONEER}

Memoirs of Bob Simpson

Robert H. Simpson with Neal M. Dorst

In 1951, Bob Simpson rode a plane directly into the wall of a hurricane-just one of his many pioneering explorations. This autobiography of the first director of the National Hurricane Research Project and co-creator of the SaffirSimpson Hurricane Scale starts with childhood rememmbrance and ends in first-hand account of a revolutionary

(c) 2014, PAPERBACK

ISBN: 978-1-935704-75-1

LIST \$30 MEMBER \$20

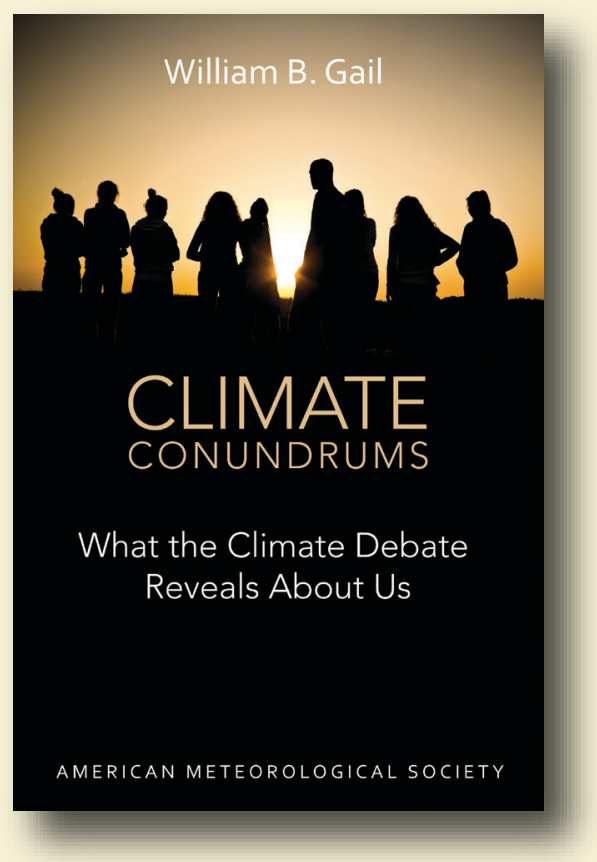

CLIMATE CONUNDRUMS What the Climate Debate Reveals About Us

William B. Gail

This is a journey through how we think, individually and collectively, derived from the climate change debate. With wit and wisdom, Gail explores several questions: Can we make nature better? Could science and religion reconcile? Insights from such issues can help us better understand who we are and help

(C) 2014, PAPERBACK

ISBN: 978-1-935704-74-4

LIST \$30 MEMBER \$20

\section{AN OBSERVER'S GUIDE TO CLOUDS AND WEATHER}

A Northeast Primer on Prediction

Toby Carlson, Paul Knight, and Celia Wyckoff

With help from Penn State experts, start at the beginning and go deep. This primer for enthusiasts and new students alike will leave you with both refined observation skills and an understanding of the complex science behind the weather: the ingredients for making reliable predictions of your own.

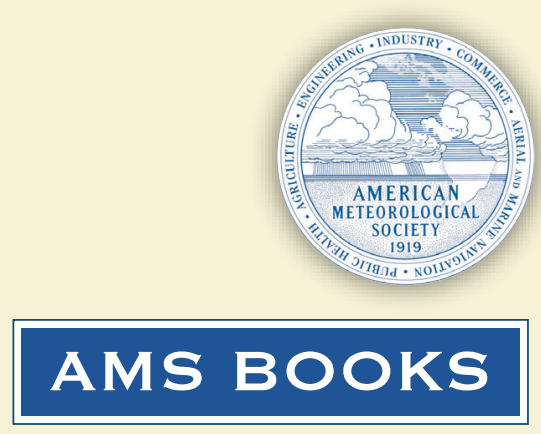

AMS Books are available to groups and booksellers, and desk copies may be obtained, through our distributor 